\title{
Incidence Of Clostridium difficile Infection And
}

\section{Associated Risk Factors Among Hospitalized Children In Qatar}

This article was published in the following Dove Press journal:

Therapeutics and Clinical Risk Management

\author{
Ahmed Khalil (D) \\ Mohamed A Hendaus ${ }^{2}$ \\ Emad Elmagboul ${ }^{3}$ \\ Asmaa Mohamed' \\ Anand Deshmukh ${ }^{3}$ \\ Ahmed Elmasoudi ${ }^{1}$ \\ 'Department of Pharmacy, Hamad \\ General Hospital, Doha, Qatar; \\ ${ }^{2}$ Department of Pediatrics, Hamad \\ Medical Corporation, Sidra Medicine, \\ Weill Cornell Medicine, Doha, Qatar; \\ ${ }^{3}$ Microbiology Laboratory, Hamad \\ General Hospital, Doha, Qatar
}

Background: Clostridium difficile infection (CDI) is the single most common cause of nosocomial diarrhea in both adults and children. There is a deficiency in the literature regarding the incidence and associated risk factors in hospitalized children. This study aimed to determine the incidence of CDI and its associated risk factors.

Methods: A retrospective study was conducted among 200 pediatric patients admitted to the pediatric ward at Hamad General Hospital (HGH) in Qatar. The study collected data from January 1, 2015 till December 2015. Univariate and multivariate logistic regression methods were used to assess each risk factor of CDI.

Results: Among the 200 patients, 23 were diagnosed with CDI (incidence: 5.9 per 1000 inpatient admission cases). The mean patient age $( \pm \mathrm{SD})$ was $6.4 \pm 3.4$ years. The incidence of antibiotic exposure (22.5; 95\% CI: 15.0-38.7; P <0.001), prolonged hospitalization (28.9; 95\% CI: 17.1-43.3; P <0.001), and enteral feeding (33.3; 95\% CI: 15.9-55.1; $\mathrm{P}<0.001)$ were significant risk factors for CDI.

Conclusion: Antibiotics exposure, prolonged hospitalization, and enteral feeding were significant risk factors of CDI in hospitalized children; thus, emphasizing the importance of antimicrobial stewardship programs in the prevention of hospital-associated infection. Further prospective studies are needed to assess the trend in incidence and to identify other risk factors of CDI.

Keywords: antimicrobial stewardship, Clostridium difficile infection (CDI), hospital acquired, hospitalized pediatric patients, risk factors

\section{Introduction}

Clostridium difficile ( $C$. difficile) is an anaerobic, gram-positive bacillus, endospore-forming bacteria and can cause infection through environmental or oralfecal routes. The first $C$. difficile infection was described in $1935 .{ }^{1} C$. difficile was first detected in stool samples of healthy neonates, leading to its classification as normal gut flora, and was not a major cause of disease until 1978. ${ }^{2,3}$ Clostridium difficile infection (CDI) ranges from self-limiting diarrhea to severe pseudo-membranous colitis, and is considered as one of the most common causes of nosocomial diarrhea in both adults and children. ${ }^{4-6}$

Latest studies have implied that CDI is emerging as a culprit of diarrhea in infants and children. ${ }^{7-9}$

This growing incidence has been insinuated, in part, to the augmented antibiotic prescriptions, the advent of a hyper-virulent strain of $C$. difficile, new and sensitive techniques to detect CDI, and increased attentiveness of CDI among clinicians. ${ }^{10,11}$
Correspondence: Ahmed Khali

Hamad General Hospital (HGH), Hamad Medical Corporation (HMC), Doha 3050, Qatar

Tel +97455078679

Email akhali17@hamad.qa 
Recently in a large multicenter retrospective analysis, children who acquired CDI after admission to the hospital had a $>6$-fold higher mortality rate than controls with similar underlying disease and risk factors. ${ }^{12}$ The only common primary risk factor for CDI in both adults and children is prior use of antibiotics. ${ }^{13,14}$

Data from North America and Europe regarding the epidemiology of CDI has illustrated the need for surveillance of the international movement of $C$. difficile strains. ${ }^{15}$ Unfortunately, in Asia insufficient data are available on CDI. A recent survey has found that awareness of CDI among clinicians Asia to be low. ${ }^{16}$

No studies regarding CDI incidence and associated risk factors has been conducted in children residing in the State of Qatar, a cosmopolitan hub where is a diversity of patients from different countries reside. The aims of this study were to evaluate the incidence of CDI and associated risk factors among pediatric inpatients at Hamad General Hospital, the only tertiary pediatric hospital in Qatar at the time of the study as well as to evaluate treatment protocols and associated outcomes (cured, failure, recurrence).

\section{Materials And Methods}

\section{Criteria For The Selection Of Patients}

This retrospective study was conducted at Hamad General Hospital, a tertiary hospital that has been accredited by the Joint Commission International (JCI) since 2006. Pediatric patients admitted from the period of January 1, 2015 till December 31, 2015 and fulfilled the inclusion criteria were involved in the study. The investigation was conducted mainly in the pediatric department which includes the general pediatric ward, the pediatric intensive care unit (PICU), pediatric hematology-oncology unit, and pediatric surgery unit. The total number of pediatric patients admitted to our hospital in 2015 was 3878 patients. The study population was 200 pediatric patients ages 2 to 14 years.

Patients were identified by reviewing the microbiology laboratory data. Data was extracted from laboratory records and from the electronic medical records (Cerner). Patient demographic data (age, sex, and diagnosis) and past medical history, medication history, and CDI treatment protocol were checked and recorded. Collected data was documented in a data collection sheet, which included variables on demographic data, types and numbers of drugs used prior to CDI (such as antimicrobials, proton pump inhibitors (PPIs), H2 receptor blockers, and chemotherapy), duration of hospitalization, CDI treatment protocol, and the outcome (treatment failure, recurrence, or cure). This study received ethical approval from the medical research committee at Hamad Medical Corporation (15457/15). As the study was retrospective, a waiver of informed consent was obtained from the research committee.Data was collected in a pre-designed data collection sheet that has been saved in a special locked cabinet accessed only by the primary investigator (PI). The data was then de-identified and entered by serial numbers only in an excel sheet in a lap top only accessed by the PI for the statistical analysis.

The following definitions, according to the guidance and recommendations from the Infectious Diseases Society of America and the Society for Healthcare Epidemiology of America, were used:

1. CDI was defined by the presence of diarrhea and at least one of these two criteria: (a) stool specimen with positive Xpert $C$. difficile ${ }^{\circledR}$ polymerase chain reaction (PCR) test (specificity $100 \%$, sensitivity 95\%), which identifies the genes (TcdB toxin and CDT binary toxin genes) associated with $C$. difficile, and a deletion in the pathogenicity locus gene TcdC at nucleotide 117 present in NAP1 ribotype 027 ; (b) or its toxins or colonoscopy or histopathologic findings demonstrating pseudo membranous colitis. ${ }^{17}$

2. CDI was defined as being hospital-acquired when the onset of symptoms occurred more than $48 \mathrm{hrs}$ after admission and less than four weeks after discharge from the hospital. ${ }^{17}$

3. Previous antibiotic treatment was defined as an antibiotic prescribed for at least $48 \mathrm{hrs}$ in the 60 days before the onset of CDI.

4. Exposure to PPIs, H2 blockers, chemotherapy, or immunosuppressant was defined as having been administered with these drugs for at least three days before the development of CDI. ${ }^{18}$

\section{Inclusion Criteria}

Children ages 2 to14 years, diagnosed with hospitalacquired CDI, and met one or more of the following criteria:

1. received antibiotics for at least $48 \mathrm{hrs}$ in the 60 days prior to $\mathrm{CDI}$; (2) prolonged hospitalization or length of stay (LOS) (more than two weeks) prior 
to CDI; (3) received PPI, H2 blocker, or chemotherapy at least three days prior to CDI; (4) malignancy, immunosuppression, inflammatory bowel disease (IBD), or cardiovascular disease (CVD), and enteral feeding or recent abdominal surgery.

\section{Exclusion Criteria}

All the patients with $C$. difficile colonization, communityacquired CDI, and those not meeting the inclusion criteria were excluded from the study.

\section{Treatment Protocol Definitions} Treatment Response

Treatment response is present when either stool frequency decreases or stool consistency improves and parameters of disease severity (clinical, laboratory, radiological) improve and no new signs of severe disease develop. In all other cases, treatment is considered a failure. ${ }^{19}$

\section{Recurrences}

Recurrence is present when CDI re-occurs within 8 weeks after the onset of a previous episode, provided the symptoms from the previous episode resolved after completion of initial treatment. ${ }^{19}$

\section{Treatment Regimens}

For mild or moderate disease C. difficile infection, it was suggested oral Metronidazole or oral Vancomycin. The dose of Metronidazole was $30 \mathrm{mg} / \mathrm{kg}$ per day by mouth in four divided doses for 10 days (maximum $500 \mathrm{mg}$ / dose). The dose of Vancomycin was $40 \mathrm{mg} / \mathrm{kg}$ per day by mouth in four divided doses (maximum $125 \mathrm{mg} / \mathrm{dose}$ ) for 10 days. ${ }^{20}$

For severe disease, it was suggested oral Vancomycin as the initial drug of choice. We used the standard oral dose for Vancomycin: $40 \mathrm{mg} / \mathrm{kg}$ per day by mouth in four divided doses (maximum $125 \mathrm{mg} /$ dose) for 10 days. $^{20}$

\section{Statistical Analysis}

Quantitative data values were expressed as frequency (percentage) and mean \pm standard deviation (SD) as well as median and range. Descriptive statistics were used to summarize demographic and all other clinical characteristics of the participants. The primary outcome variable, which is the incidence of CDI, was estimated and presented with a $95 \%$ confidence interval (CI). Associations between two or more quantitative variables were assessed using chi-square and Fisher exact tests, as appropriate.
Quantitative data between two independent groups ( $C$. difficile-positive vs -negative) were analysed and compared using unpaired t-tests Results were presented with 95\% CIs. Univariate and multivariate logistic regression methods were used to assess the predictive values of each probable predictor or risk factor associated with CDI. For multivariate regression models, covariates and predictors were considered if statistically significant at the $\mathrm{P}<0.10$ level in univariate analysis or if determined to be clinically important. Potential interactions were also included in the logistic regression model. The results of logistic regression analyses were reported as odds ratio (OR) with 95\% CIs. Graphical representations of key results were made using appropriate statistical graphs. A two-sided P-value $<0.05$ was considered to be statistically significant. All statistical analyses were done using statistical packages SPSS 22.0 (Armonk, NY: IBM Corp) and Epi Info 2000 (Center for Disease Control and Prevention, Atlanta, GA, USA).

\section{Results}

\section{The Sociodemographic And Clinical Characteristics Of Participants With Clostridium difficile Infection}

During the study period, 200 participant's ages between 2 and 14 years were enrolled and screened. The mean age of the enrolled patients was $7.3 \pm 3.8$ years, and the male to female ratio was 2.4:1. Clostridium difficile testing was obtained from all participants as all of them had diarrhea and at least one of the risk factors as well.

\section{Incidence Of Clostridium difficile By Demographic And Other Clinical Characteristics}

Among the 200 participants, 23 (incidence: 11.6\%; 95\% CI: 7.6 to 16.5 ) were $C$. difficile positive, while 177 (88.5\%) were $C$. difficile negative. The participants in the C. Difficile positive group were younger than those in the C. difficile negative group (mean age: $6.4 \pm 3.4$ years vs 7.3 \pm 3.8 years; $\mathrm{P}=0.290$ ). Table 1 portrays the incidence of C. difficile by age, sex, and other clinical characteristics.

Next the incidence of CDI according to potential risk factors was determined. The incidence of $C$. difficile in the antibiotic exposure group was significantly higher $(22.5 \%$; 95\% CI: $15-38.7 \%$ ) than that of the antibiotic free group (6.7\%; 95\% CI: $3.5-11.6 \%$; $\mathrm{P}<0.001)$. The incidence of C. difficile was significantly higher in participants with 
Table I Incidence Of Clostridium difficile By Demographic And Other Clinical Characteristics

\begin{tabular}{|c|c|c|c|}
\hline Mean \pm SD & $n / N$ & $\begin{array}{l}\text { Percent Incidence } \\
(95 \% \mathrm{Cl})\end{array}$ & $P$-value \\
\hline $\begin{array}{l}\text { Overall Age Group } \\
\leq 5 \text { years } \\
5 \text { to } 10 \text { years } \\
>10 \text { years } \\
\text { Age (years) } 6.4 \pm 3.4 \text {; range } \\
(2,14)\end{array}$ & $\begin{array}{l}23 / 200 \\
13 / 92 \\
8 / 59 \\
2 / 49\end{array}$ & $\begin{array}{l}11.6(7.6,16.5) \\
14.1(8.1,22.4) \\
13.6(6.5,24.1) \\
4.1(0.69,12.8)\end{array}$ & 0.172 \\
\hline $\begin{array}{l}\text { Sex } \\
\text { Male } \\
\text { Female }\end{array}$ & $\begin{array}{l}19 / 142 \\
4 / 58\end{array}$ & $\begin{array}{l}13.4(8.5,19.7) \\
6.9(2.2,15.8)\end{array}$ & 0.192 \\
\hline $\begin{array}{l}\text { Antibiotic exposure } \\
\text { Yes } \\
\text { No }\end{array}$ & $\begin{array}{l}13 / 5 \mid \\
10 / 149\end{array}$ & $\begin{array}{l}22.5(15,38.7) \\
6.7(3.5,11.6)\end{array}$ & $<0.001$ \\
\hline $\begin{array}{l}\text { Prolonged LOS } \\
\text { Yes } \\
\text { No }\end{array}$ & $\begin{array}{l}13 / 45 \\
10 / 155\end{array}$ & $\begin{array}{l}28.9(17.1,43.3) \\
6.5(3.3,11.2)\end{array}$ & $<0.001$ \\
\hline $\begin{array}{l}\text { Chemo\& } \\
\text { immunosuppressant } \\
\text { Yes } \\
\text { No }\end{array}$ & $\begin{array}{l}10 / 68 \\
13 / 132\end{array}$ & $\begin{array}{l}14.7(7.7,24.7) \\
9.8(5.6,15.9)\end{array}$ & 0.308 \\
\hline $\begin{array}{l}\text { PPI } \\
\text { Yes } \\
\text { No }\end{array}$ & $\begin{array}{l}10 / 64 \\
13 / 136\end{array}$ & $\begin{array}{l}15.6(8.2,26.1) \\
9.6(5.4,15.4)\end{array}$ & 0.210 \\
\hline $\begin{array}{l}\text { H2 blocker } \\
\text { Yes } \\
\text { No }\end{array}$ & $\begin{array}{l}5 / 42 \\
18 / 158\end{array}$ & $\begin{array}{l}11.9(4.5,24.4) \\
11.4(7.1,17.1)\end{array}$ & 0.926 \\
\hline $\begin{array}{l}\text { Enteral feeding } \\
\text { Yes } \\
\text { No }\end{array}$ & $\begin{array}{l}7 / 21 \\
16 / 179\end{array}$ & $\begin{array}{l}33.3(15.9,55.1) \\
8.9(5.4,13.8)\end{array}$ & 0.001 \\
\hline $\begin{array}{l}\text { Recent abdominal surgery } \\
\text { Yes } \\
\text { No }\end{array}$ & $\begin{array}{l}1 / 6 \\
22 / 194\end{array}$ & $\begin{array}{l}16.7(0.83,59.1) \\
11.3(7.4,16.4)\end{array}$ & 0.687 \\
\hline $\begin{array}{l}\text { Malignancy } \\
\text { Yes } \\
\text { No }\end{array}$ & $\begin{array}{l}7 / 54 \\
16 / 146\end{array}$ & $\begin{array}{l}\text { I3 }(5.8,24) \\
\text { II }(6.6,16.8)\end{array}$ & 0.693 \\
\hline $\begin{array}{l}\text { IBD } \\
\text { Yes } \\
\text { No }\end{array}$ & $\begin{array}{l}0 / 54 \\
23 / 146\end{array}$ & $\begin{array}{l}0(0,31.2) \\
12(7.9,17.2)\end{array}$ & 0.298 \\
\hline $\begin{array}{r}\text { CVD } \\
\text { Yes } \\
\text { No }\end{array}$ & $\begin{array}{l}1 / 5 \\
22 / 195\end{array}$ & $\begin{array}{l}20(1,66.6) \\
11.3(7.4,16.3)\end{array}$ & 0.546 \\
\hline $\begin{array}{l}\text { Immunodeficiency } \\
\text { Yes } \\
\text { No }\end{array}$ & $\begin{array}{l}4 / 15 \\
19 / 185\end{array}$ & $\begin{array}{l}26.7(9.1,52.5) \\
10.3(6.5,15.3)\end{array}$ & 0.056 \\
\hline
\end{tabular}

Abbreviations: $\mathrm{Cl}$, confidence interval; LOS, length of stay; chemo, chemotherapy; PPI, proton pump inhibitor; IBD, inflammatory bowel disease; CVD, cardiovascular disease; SD, standard deviation; $\mathrm{n} / \mathrm{N}, \mathrm{n}$ for positive/negative cases, $\mathrm{N}$ for total number of each group. prolonged hospital length of stay (LOS) $(28.9 \%$; $95 \%$ CI: $17.1-43.3 \%)$ when compared to non-prolonged LOS (6.5\%; 95\% CI: $3.3-11.2 \%$; $<<0.001)$. Similarly, the incidence of $C$. difficile was significantly higher in the enteral feeding $(33.3 \%)$ group than in the non-enteral feeding $(8.9 \% ; \mathrm{P}=0.001)$ group. However, there was no significant differences were found in the incidence of the other potential risk factors (age, sex, chemotherapy and immunosuppressant, H2 blockers, recent abdominal surgery, malignancy, IBD, CVD, and immunodeficiency) (Table 1). Although there was a trend towards a higher Clostridium difficile incidence in participants who were younger than 5 years $(14.1 \%$; 95\% CI: 8.1-22.4\%) when compared to those aged 5 to 10 years $(13.6 \%$; $95 \% \mathrm{CI}$ : 6.5-24.1\%), and more than 10 years $(4.1 \%$; $95 \%$ CI: 0.69 $12.8 \%)$, these differences were not significant ( $\mathrm{P}=0.172)$. Additionally, while we observed a trend towards a higher Clostridium difficile incidence in male participants (13.4\%; 95\% CI: 8.5-19.7\%) than in female participants (6.9\%; 95\% CI: $2.2-15.8 \%)$, this was not statistically significant $(\mathrm{P}=0.192)$.

\section{Common Antibiotics Used Prior To Clostridium difficile Infection And The Outcomes Among Infected Patients}

The types of antibiotics prescribed to the patients prior to CDI were checked. Piperacillin-Tazobactam (7/23 (29.1\%)) was the most commonly prescribed antibiotic. Figure 1 shows the common antibiotics that were used before CDI.

\section{Treatment And Outcomes}

Among the 23 positive $C$. difficile cases that fulfilled the criteria for CDI, 17 (74\%) were cured, while $6(26 \%)$ had recurrent infection; however, no treatment failure occurred among the cases. Metronidazole was administered in 22 cases, of which 16 (72.7\%) were cured and 6 (27.3\%) cases had a recurrent infection. There was only one severe case of CDI, which was initially treated with Vancomycin, resulting in successful treatment.

\section{Association Of Various Predictors And Risk Factors With Clostridium difficile Potential Risk Factors Associated With CDI}

The results of the logistic regression analysis for each predictive variable and probable risk factor, and its association with $C$. difficile are presented in Table 2. Logistic regression 


\section{No of cases (\%)}

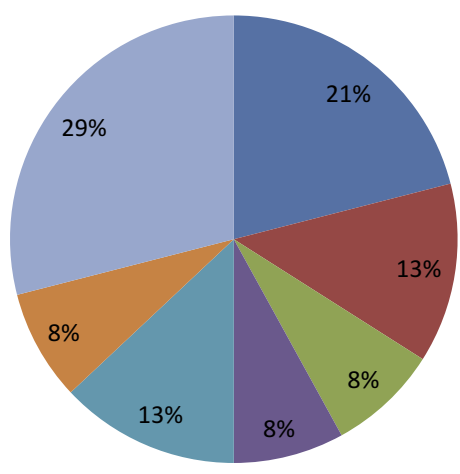

Amox-Clavulanate

- Cefepime

Ceftriaxone

- Ciprofloxacin

Meropenem

- Co-Trimoxazole

- Piperacillin-Tazobactam

Figure I Common antibiotics used prior to C. difficile infection.

analysis revealed that antibiotic exposure, prolonged LOS, and enteral feeding were significantly associated with an increased risk of CDI. The risk of CDI was 4.8 times more likely in the antibiotic exposure group $(\mathrm{OR}=4.8 ; 95 \% \mathrm{CI}$ :

Table 2 Association Of Various Predictors And Risk Factors With Clostridium difficile: Univariate Logistic Regression Analysis

\begin{tabular}{|c|c|c|c|}
\hline & $\begin{array}{l}\text { Unadjusted Odds } \\
\text { Ratio (OR) }\end{array}$ & $\begin{array}{l}95 \% \mathrm{Cl} \\
\text { For OR }\end{array}$ & P-value \\
\hline \multicolumn{4}{|l|}{ Age Group } \\
\hline 5 years & 3.9 & $0.84,17.9$ & 0.084 \\
\hline 5 to 10 years & 3.7 & $0.75,18.2$ & 0.110 \\
\hline$>10$ years $\dagger$ & 1.0 & & \\
\hline \multicolumn{4}{|l|}{ Sex } \\
\hline Male & 2.1 & $0.68,6.4$ & \\
\hline Female $\nmid$ & 1.0 & & 0.200 \\
\hline Antibiotic exposure & 4.8 & $1.9,11.7$ & 0.001 \\
\hline Prolonged LOS & 5.9 & $2.4,14.6$ & $<0.001$ \\
\hline $\begin{array}{l}\text { Chemo\& } \\
\text { Immunosuppressant }\end{array}$ & 1.6 & $0.65,3.8$ & 0.311 \\
\hline PPI & 1.8 & $0.72,4.2$ & 0.214 \\
\hline $\mathrm{H} 2$ blocker & I.I & $0.37,3.1$ & 0.926 \\
\hline Enteral feeding & 5.1 & I.8, 14.4 & 0.002 \\
\hline $\begin{array}{l}\text { Recent abdominal } \\
\text { surgery }\end{array}$ & 1.6 & $0.18,14.1$ & 0.689 \\
\hline Malignancy & 1.2 & $0.47,3.1$ & 0.694 \\
\hline CVD & 2.1 & $0.21,18.4$ & 0.553 \\
\hline Immunodeficiency & 3.2 & $0.92,11.1$ & 0.067 \\
\hline
\end{tabular}

Note: $\nmid$ Subjects in this category served as the reference group.

Abbreviations: OR, odds ratio; $\mathrm{Cl}$, confidence interval; LOS, length of stay; chemo, chemotherapy; PPI, proton pump inhibitor; CVD, cardiovascular disease.

1.9-11.7; $\mathrm{P}=0.001$ ) compared to the antibiotic free group. Participants who were positive for CDI were nearly 6 times as likely to have prolonged $\operatorname{LOS}(\mathrm{OR}=5.9 ; 95 \% \mathrm{CI}: 2.4$ 14.6; $\mathrm{P}<0.001), 5.1$ times as likely to have enteral feeding $(\mathrm{OR}=5.1 ; 95 \% \mathrm{CI}: 1.8-14.4 ; \mathrm{P}=0.002)$ compared to those who tested negative for CDI. In the multivariate logistic regression analysis, while controlling for all other potential covariates and predictors such as age, sex, antibiotic exposure, prolonged LOS, enteral feeding, PPI, H2 blocker, recent abdominal surgery, chemotherapy and Immunosuppressant, CVD, and immunodeficiency, we found that the predictors with the strongest and most significant association with CDI are antibiotic exposure, prolonged LOS and enteral feeding (adjusted odds ratio are shown in Table 3).

\section{Discussion}

Published reports of CDI incidence in hospitalized children has been historically low, but currently might be on the rise. Kim et $\mathrm{al}^{7}$ reported an increase from 2.6 to 4 cases per 1000 admissions in twenty-two US children hospitals over a five-year period from 2001 to 2006. Similar results were also documented in a study by Zilberberget et $\mathrm{al}^{21}$ where an increase in hospitalacquired CDI in the pediatric population was reported. In Qatar, one study has been conducted to determine the prevalence of CDI and its associated ribotypes isolates. Cases were recruited from two hospitals (hospitalized and community cases). They reported that 122 of the $1532(7.9 \%)$ samples, from a mixed population (adults and children), were identified as $C$. difficile positive. ${ }^{22}$ In our hospital, an adult study was also conducted among inpatients from 2006 to 2009 with an estimated overall incidence of 1.6 cases per 10,000 patients. $^{23}$ However, our children study has shown a CDI incidence of 5.9 per 1000 inpatient admission cases.

The rate of colonization of $\mathrm{C}$. difficile in pediatric cases younger than two years can range between 33 and

Table 3 Association Of Various Predictors And Risk Factors With Clostridium difficile: Multivariate Logistic Regression Analysis

\begin{tabular}{|l|l|l|l|}
\hline & $\begin{array}{l}\text { Adjusted Odds Ratio } \\
\text { (OR) }\end{array}$ & $\begin{array}{l}\text { 95\% CI For } \\
\text { OR }\end{array}$ & $\begin{array}{l}\text { P- } \\
\text { value }\end{array}$ \\
\hline $\begin{array}{l}\text { Antibiotic } \\
\text { exposure }\end{array}$ & 9.2 & $2.6,32.4$ & 0.001 \\
Prolonged LOS & 7.2 & $2.2,23.6$ & 0.001 \\
Enteral feeding & 7.2 & $1.7,31.3$ & 0.008 \\
\hline
\end{tabular}

Abbreviations: $\mathrm{OR}$, odds ratio; $\mathrm{Cl}$, Confidence interval; LOS, length of stay. 
$70 \% \cdot{ }^{24,25}$ For this reason, we limited our study to patients aged 2 years or older, and no older than 14 years.

We observed a higher CDI incidence in participants younger than five years $(14.1 \%)$, compared to those aged five to ten years $(13.6 \%)$, and over ten years $(4.1 \%)$. These results indicate which age group is more likely to have the infection. Our results are consistent with findings from studies by Zilberberg et $\mathrm{al}^{21}$ and Duleba et $\mathrm{al}^{26}$ where the highest incidence of hospitalized CDI was observed in children aged up to 4 years $(44.9 / 10,000)$.

Certain factors can lead to an increased risk of CDI. Antibiotic exposure is considered one of the most significant risk factor for developing CDI in both adults and children, and most antibiotic classes have been associated with CDI. ${ }^{13}$ There was a significant increase $(\mathrm{P}<0.001)$ in the incidence of CDI in the antibiotic-exposed group in our study with $22.5 \%$ compared with $6.7 \%$ in the unexposed antibiotic group. This is consistent with reports from previous studies which reported that Clindamycin, cephalosporin, and Fluoroquinolones are most commonly associated with CDI. ${ }^{9,13,27}$ However, in this study, we found that the antibiotic most often received prior to CDI cases was Piperacillin-Tazobactam, which had been administered in $7(29.1 \%)$ of 24 cases.

The establishment of an antimicrobial stewardship program in our hospital is critically necessary. This program, together with strict adherence to infection control policies, will help decrease and prevent the development of hospital-acquired CDI. Several studies mentioned the importance and the role of such restrictions in the use of antibiotics to control the incidence of CDI. ${ }^{28,29}$ The results of these studies and others highlight the importance of implementing antimicrobial stewardship programs to the prevention of hospitalization-associated infection. ${ }^{30,31}$ The Society for Healthcare Epidemiology of America and the Infectious Diseases Society of America have published guidelines for the appropriate use of the antimicrobial agents through institutional antimicrobial stewardship programs. $^{32}$

Hospitalization may be an isolated risk factor for developing CDI, or may be associated with additional risk factors, such as antibiotic exposure or other healthcare procedures. The risk of infection increases with prolonged hospitalization. ${ }^{27,33}$ In our study, patients with prolonged hospitalization had a higher incidence (28.9\%) of CDI.

While reviewing the literature, enteral feeding (mainly nasogastric feeding) is reported to be a risk factor for developing CDI in both adult and pediatric populations.
One study, which used a multivariate analysis for enteral feeding as a risk factor of CDI, showed an odds ratio of 19.7. ${ }^{34}$ Another study also reported a statistically significant association between enteral feeding and CDI ( $\mathrm{P}$ $=0.04) .{ }^{35}$ Our study found significantly higher CDI incidence in participants with prior enteral feeding compared to non-enteral feeding cases $(33.3 \%$ vs $8.9 \%, \mathrm{P}=0.001)$.

The first-line treatment for CDI recommended by the American Academy of Pediatrics is Metronidazole. Nevertheless, some evidence support the use of oral vancomycin treating CDI in adults, especially in severe cases. ${ }^{36}$ The majority of our cases were mild cases, with only one severe infection. All 22 mild cases were treated with Metronidazole leading to cure of $16(72.7 \%)$ cases, while6 $(27.3 \%)$ had relapse. The severe case was initially treated and cured with vancomycin. In total, 17 cases (74\%) were cured from the first attempt and 6 cases $(26 \%)$ had recurrent infection. No treatment failure was reported. The percentage of the recurrent infection that we have reported is similar to previously published study, where approximately $30 \%$ of pediatric cases had recurrent $\mathrm{CDI} .{ }^{27}$ Discontinuation of these antibiotics can be the initial step of the treatment in those cases of CDI where antibiotics were the culprits. In our study, discontinuation of the responsible antibiotics occurred in only 5 of 13 (38.5\%) cases. In the remaining cases, antibiotics could not be discontinued due to the severe infection.

This study had some limitations. As this was a retrospective study, the retrospective design can introduce bias, including inadequate identification of variables for analysis. The study had small, hospital-specific samples; hence, results may not be applicable to other hospitals despite the diversity in the cases included in the study. The duration of the study was also short (one year). Despite these limitations, this study provided valuable insight as the first study to focus on the incidence, significance, and risk factors for hospital-acquired CDI in a pediatric population in Qatar.

\section{Conclusion}

Prior exposure to antibiotics and prolonged hospitalization remain fundamental risk factors for the CDI in hospitalized children. In addition, our study highlighted enteral feeding as a risk factor as well. Further prospective studies are needed to assess the incidence of CDI trend in our hospital to either detect an increase or a decrease and to identify other risk factors for CDI. Additionally, our results highlight the importance of antimicrobial stewardship programs in the prevention of hospitalization-associated infection. 
Significant efforts are required to prevent the spread of this infection in hospitals and medical centers, with a focus on infection control protocols and antimicrobial stewardship programs.

\section{Acknowledgement}

The abstract of this research study was presented at the American Academy of Pediatrics National Conference \& Exhibition in Orlando, Florida (2018). Our study complies with Declaration of Helsinki.

\section{Disclosure}

The authors report no conflicts of interest in this work.

\section{References}

1. Hall IC, O'Toole EL. Intestinal flora in new-born infants: with a description of a new pathogenic anaerobe, Bacillus difficilis. Am J Dis Child. 1935;49:390-402. doi:10.1001/archpedi.1935.019700201 05010

2. George RH, Symonds JM, Dimock F, et al. Identification of Clostridium difficile as a cause of pseudomembranous colitis. BMJ. 1978;1:695. doi:10.1136/bmj.1.6114.695

3. Larson HE, Price AB, Honour P, et al. Clostridium difficile and the etiology of pseudomembranous colitis. The Lancet. 1978;311:10631066. doi:10.1016/S0140-6736(78)90912-1

4. Dubberke ER, Gerding DN, Classen D, et al. Strategies to prevent Clostridium difficile infections in acute care hospitals. Infect Control Hosp Epidemiol. 2008;29Suppl 1:S81-92.

5. Langley JM, LeBlanc JC, Hanakowski M, et al. The role of Clostridium difficile and viruses as causes of nosocomial diarrhea in children. Infect Control Hosp Epidemiol. 2002;23:660-664.

6. Magill SS, Edwards JR, Bamberg W, et al. Multistate point-prevalence survey of health care-associated infections. $N$ Engl J Med. 2014;370:1198-1208. doi:10.1056/NEJMoa1306801

7. Kim J, Smathers SA, Prasad P, Leckerman KH, Coffin S, Zaoutis T. Epidemiological features of Clostridium difficile-associated disease among inpatients at children's hospitals in the United States, 2001-2006. Pediatrics. 2008;122:1266-1270. doi:10.1542/peds.20 08-0469

8. Enoch DA, Butler MJ, Pai S, Aliyu SH, Karas JA. Clostridium difficile in children: colonisation and disease. J Infect. 2011;63:105113. doi:10.1016/j.jinf.2011.05.016

9. Benson L, Song X, Campos J, Singh N. Changing epidemiology of Clostridium difficile-associated disease in children. Infect Control Hosp Epidemiol. 2007;28:1233-1235. doi:10.1086/520732

10. Khanna S, Pardi DS. The growing incidence and severity of Clostridium difficile infection in inpatient and outpatient settings. Expert Rev Gastroenterol Hepatol. 2010;4:409-416. doi:10.1586/ egh. 10.48

11. Kelly CP, LaMont JT. Clostridium difficile - more difficult than ever. $N$ Engl J Med. 2008;359:1932-1940. doi:10.1056/NEJMra0707500

12. Sammons JS, Localio R, Xiao R, et al. Clostridium difficile infection is associated with increased risk of death and prolonged hospitalization in children. Clin Infect Dis. 2013;57:1-8.

13. Owens RC Jr, Donskey CJ, Gaynes RP, et al. Antimicrobial-associated risk factors for Clostridium difficile infection. Clin Infect Dis. 2008;46 Supplement_1:S19-S31.

14. Schutze GE, Willoughby RE. American academy of pediatrics. Infection in Infants and Children. Pediatrics. 2013;131:196-200.
15. Clements AC, Magalhaes RJ, Tatem AJ, Paterson DL. Riley TV: Clostridium difficile PCR ribotype 027: assessing the risks of further worldwidespread. Lancet Infect Dis. 2010;10(6):395-404. doi:10. 1016/S1473-3099(10)70080-3

16. Mavros MN, Alexiou VG, Vardakas KZ, Tsokali K, Sardi TA. FalagasME:underestimation of Clostridium difficile infection among clinicians: an international survey. Eur J ClinMicrobiol Infect Dis. 2012;31(9):2439-2444. doi:10.1007/s10096-012-1587-9

17. Cohen SH, Gerding DN, Johnson S, et al. Clinical practice guidelines for Clostridium difficile infection in adults: 2010 update by the society for healthcare epidemiology of America (SHEA) and the infectious diseases society of America (IDSA). Infect Control Hosp Epidemiol. 2010;31:431-455. doi:10.1086/651706

18. Barletta JF, Sclar DA. Proton pump inhibitors increase the risk for hospital-acquired Clostridium difficile infection in critically ill patients. Crit Care. 2014;18:714. doi:10.1186/s13054-014-07 14-7

19. Debast SB, Bauer MP, Kuijper EJ. European Society of clinical microbiology and infectious diseases: update of the treatment guidance document for Clostridium difficile infection. Clin Microbiol Infect. 2014;1(20):1-26. doi:10.1111/1469-0691.12418

20. D'Ostroph AR, So TY. Treatment of pediatric Clostridium difficile infection: a review on treatment efficacy and economic value. Infect Drug Resist. 2017;10:365. doi:10.2147/IDR.S119571

21. Zilberberg MD, Tillotson GS, McDonald C. Clostridium difficile infections among hospitalized children, United States, 1997-2006. Emerg Infect Dis. 2010;16:604-609. doi:10.3201/eid 1604.090680

22. Al-Thani AA, Hamdi WS, Al-Ansari NA, et al. Polymerase chain reaction ribotyping of Clostridium difficile isolates in Qatar: a hospital-based study. BMC Infect Dis. 2014;14:502. doi:10.1186/14712334-14-502

23. Khan FY, Abu-Khattab M, Anand D, et al. Epidemiological features of Clostridium difficile infection among inpatients at Hamad General Hospital in the state of Qatar, 2006-2009. Travel Med Infect Dis. 2012;10:179-185. doi:10.1016/j.tmaid.2012.06.004

24. Bryant K, McDonald LC. Clostridium difficile infections in children. The Pediatr Infect Dis J. 2009;28:145-146. doi:10.1097/INF. 0b013e318198c984

25. Rousseau C, Lemée L, Le Monnier A, et al. Prevalence and diversity of Clostridium difficile strains in infants. $J$ Med Microbiol. 2011;60:1112-1118. doi:10.1099/jmm.0.029736-0

26. Duleba K, Pawłowska M, Wietlicka-Piszcz M. Clostridium difficile infection in children hospitalized due to diarrhea. Eur J Clin Microbiol. 2014;33:201-209.

27. Morinville V, McDonald J. Clostridium difficile-associated diarrhea in 200 Canadian children. Can J Gastroenterol Hepatol. 2005; 19:497-501.

28. Khan R, Cheesbrough J. Impact of changes in antibiotic policy on Clostridium difficile-associated diarrhoea (CDAD) over a five-year period in a district general hospital. J Hosp Infect. 2003;54:104-108. doi:10.1016/S0195-6701(03)00115-4

29. Muto CA, Pokrywka M, Shutt K, et al. A large outbreak of Clostridium difficile-associated disease with an unexpected proportion of deaths and colectomies at a teaching hospital following increased fluoroquinolone use. Infect Control Hosp Epidemiol. 2005;26:273-280.

30. Muto CA, Blank MK, Marsh JW, et al. Control of an outbreak of infection with the hypervirulent Clostridium difficile BI strain in a university hospital using a comprehensive" bundle" approach. Clin Infect Dis. 2007;45:1266-1273. doi:10.1086/522654

31. Valiquette L, Cossette B, Garant MP, et al. Impact of a reduction in the use of high-risk antibiotics on the course of an epidemic of Clostridium difficile-associated disease caused by the hypervirulent NAP1/027 strain. Clin Infect Dis. 2007;45(Supplement 2):S112-21. doi:10.1086/519258 
32. Dellit TH, Owens RC, McGowan JE, et al. Infectious diseases society of america and the society for healthcare epidemiology of America guidelines for developing an institutional program to enhance antimicrobial stewardship. Clin Infect Dis. 2007;44:159-177. doi:10.10 $86 / 510393$

33. Bignardi GE. Risk factors for Clostridium difficile infection. J Hosp Infect. 1998;40:1-15. doi:10.1016/S0195-6701(98)90019-6

34. Talon D, Bailly P, Delmée M, et al. Use of pulsed-field gel electrophoresis for investigation of an outbreak of Clostridium difficile infection among geriatric patients. Eur J Clin Microbiol. 1995;14:987-993.
35. Loo VG, Poirier L, Miller MA, et al. A predominantly clonal multiinstitutional outbreak of Clostridium difficile-associated diarrhea with high morbidity and mortality. N Engl J Med. 2005;353:24422449. doi:10.1056/NEJMoa051639

36. Zar FA, Bakkanagari SR, Moorthi KM, et al. A comparison of vancomycin and metronidazole for the treatment of Clostridium difficile-associated diarrhea, stratified by disease severity. Clin Infect Dis. 2007;45:302-307. doi:10.1086/519265

\section{Publish your work in this journal}

Therapeutics and Clinical Risk Management is an international, peerreviewed journal of clinical therapeutics and risk management, focusing on concise rapid reporting of clinical studies in all therapeutic areas, outcomes, safety, and programs for the effective, safe, and sustained use of medicines. This journal is indexed on PubMed Central, CAS,
EMBase, Scopus and the Elsevier Bibliographic databases. The manuscript management system is completely online and includes a very quick and fair peer-review system, which is all easy to use. Visit http://www.dovepress.com/testimonials.php to read real quotes from published authors. 